\title{
Tooth Size Discrepancies among Different Malocclusions in a Bangladeshi Orthodontic population
}

Hyder MLA ${ }^{1}$ BDS, FCPS, Mamun MSA ${ }^{2}$ BDS, FCPS and Hossain MZ $^{3}$ BDS, PhD

\begin{abstract}
Objectives: To identify the possible sex differences in anterior, posterior, and overall tooth size ratios and to evaluate whether any differences exist in tooth size ratios and distribution of subjects with clinically significant tooth size discrepancies among Angle class I, class II, \& class III malocclusion groups in Bangladeshi Orthodontic population.
\end{abstract}

Materials and Methods: Each malocclusion group comprised 40 subjects ( 20 males and 20 females).The mesiodistal width from first molar to first molar were measured on each pretreatment cast to the nearest $0.01 \mathrm{~mm}$ using digital calipers, and the anterior, posterior and overall ratios were calculated. Students t-test, Wilcoxon nonparametric test, analysis of variance, and $\mathrm{x}^{2}$-test were performed for statistical analysis.

Results: No statistically significant differences in anterior, posterior, or overall ratios were found among the malocclusion groups. No significant sex differences were found in anterior, posterior, or overall ratio in any group, Significant anterior and overall tooth size discrepancies outside 2 SD from the Bolton's means were found in $31 \%$ and $11.6 \%$ of all malocclusion subjects respectively.

Conclusion: Bolton's values can be used with confidence for the Bangladeshi orthodontic population.

Key words: Anterior ratio; Posterior ratio: Overall ratio: Tooth size discrepancy: Malocclusion; Bangladeshi population (Bangladesh Journal of Orthodontics and Dentofacial Orthopedics, Vol. 2, No. 2, April 2012, p 8-17).

\section{INTRODUCTION}

Andrews (1972) studied the dental casts of 120 non orthodontic individuals with normal occlusion and concluded that there are six essential 'keys' required to achieve this normal occlusion'1. Maclaughlin et al (2001) stated that tooth size should be considered 'seventh key' and that without coordination between the sizes of the upper and lower teeth it would not be possible to obtain a good occlusion during the final stages of orthodontic treatment. The lack of co-ordination is called 'TOOTH SIZE DISCREPANCY' (TSD).

Profit (2007) 2 defined TSD as a disproportion among the sizes of the individual teeth. A correct maxillary to mandibular tooth size ratio is essential for the achievement of correct occlusal interdigitation, overjet, and overbite. Without an appropriate relationship of mesiodistal tooth dimensions of the maxillary and mandibular teeth, coordination of the arches would be difficult with consequences on the final orthodontic treatment result and its stability. $3,4,5$

Bolton(1958) 4 investigated the relationship between the mesiodistal crown diameters of the upper and lower teeth and developed an analysis. This analysis was carried out by measuring the mesiodistal width of each permanent tooth. In the calculation of a possible TSD the sum of the diameters of the mandibular teeth is divided by that of maxillary teeth and the result multiplied by 100 . For evaluation of the two sets of 12 opposing teeth, the term 'overall ratio' is used and for the two sets six anterior teeth, the term 'anterior ratio'. Bolton stated that for a good interdigitation and occlusion, overall ratio should be $91.3 \pm 1.91$ and anterior ratio77.2 \pm 1.65 . Clinical application of the analysis has been described by Bolton(1962). ${ }^{5}$

In Bangladesh two studies have been conducted on "Bolton's anterior tooth size discrepancies in different malocclusion groups". No studies have yet been conducted on posterior and overall tooth size discrepancies in Bangladeshi Orthodontic population. Therefore this study focused on anterior, posterior and overall TSD in different malocclusion groups in Bangladeshi Orthodontic population. This study is the first of its nature to be conducted to establish a norm of TSD in Bangladesh using electronic digital caliper.

\section{MATERIALS \& METHODS}

The sample for this study consisted of 120 subjects subdivided into three types of malocclusion according to the Angle classification classes I, II and III. All the subjects were from Bangladeshi Orthodontic population and were between 12 to 24 years of age. The subjects with varying malocclusions were selected from the Orthodontic patients who had received treatment in the Department of Orthodontics, Dhaka Dental College and Hospital, Dhaka. 


\section{Selection criteria}

Inclusion criteria:

1. Good quality of pretreatment models.

2. Complete permanent dentition from 6 to 6 .

3. Abscence of mesiodistal and occlusal abrasions or caries or classII fillings.

4. Absence of dental prosthesis

5. Absence of tooth anomalies such as form, structure, and development, whereas the less objectionable anomalies such as microdontia and macrodontia were included. Cases of fusion of teeth and germination were excluded because it was not possible to analyse the specific size of teeth, whereas the presence of conical teeth was not considered an exclusion criteria because it represented the morphological identity of these teeth.

\section{Exclusion criteria}

1. Gross restorations, buildups, crowns, onlays, class II amalgams or composite restorations that affect the tooth's mesiodistal diameter.

2. Congenital defects or deformed teeth.

3. Obvious interproximal or occlusal wear of teeth.

The mesiodistal dimentions of all teeth on each cast from first molar to first molar were measured with digital callipers accurate to $0.01 \mathrm{~mm}$. The Mesiodistal dimension of each tooth was measured according to the method described by Moorrees et al. $(1957)^{8}$, from its mesial contact point to its distal contact point at its greatest interproximal distance. All mesurments, carried out under natural light and were performed by the same investigator, who did not exceed more than seven casts per day in order to avoid eye fatigue and to minimize the possibility of subjective error.

Diagram to show areas where Anterior, Posterior and Over all ratios have been measured

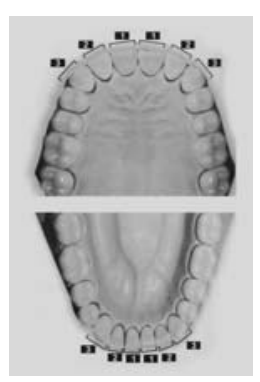

Anterior ratio

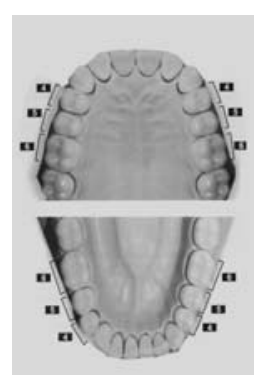

Posterior ratio

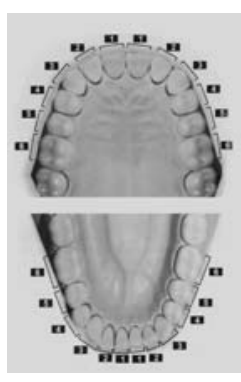

Over all ratio

\section{Data measuring Instrument}

This digital Caliper have been used to measure the mesiodistal tooth dimension of upper and lower jaw.
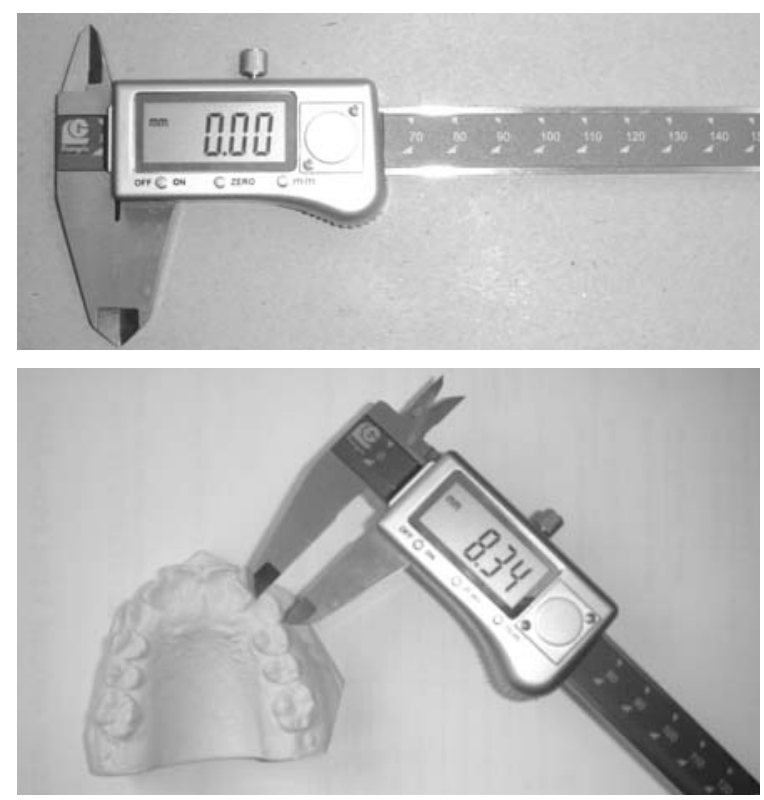

Example of mesio-distal tooth measurement with digital caliper

Bolton's analysis was performed on each set of models, when the teeth of all subjects had been measured. The anterior, posterior and overall tooth size ratios were determined using the following formula;

$\frac{\text { Sum of mandibular3 }-3}{\text { Sum of maxillary 3-3 }} \times 100=$ anterior ratio

$\frac{\text { Sum of mandibular } 654-456}{\text { Sum of maxillary } 654-456} \times 100=$ posterior ratio

$\frac{\text { Sum of mandibular 6-6 }}{\text { Sum of maxillary 6-6 }} \times 100=$ overall ratio

Bolton normal range values were used in the classification of normal and malocclusion groups. According to the Bolton analysis, a significant discrepancy was defined as one whose value was outside of 2SD from Bolton mean and approximately $95 \%$ of Bolton cases were within this range. Therefore, for the overall "12" ratio, a significant discrepancy is defined as a ratio below 87.5or above 95.1,with ratio in-between falling within 2SD of Bolton mean. Similarly, any ratio below 73.9 or above 80.5 is considered to be a significant discrepancy for the anterior "6" ratio. 


\section{STATISTICAL ANALYSIS}

The subjects were divided by gender and by Angles malocclusion classes. Statistical analysis were carried out using the Soft ware STATA(International standard) version 9. The results are summarized in different tables. To determine whether there was gender dimorphism in the incidence of tooth size discrepancies a student's t-test was performed. For each malocclusion group, the level of significance was set at 0.005 . In order to compare inter maxillary tooth size discrepancies among different malocclusion groups, one way analysis of variance (ANOVA) was performed. In order to determine the percentage of tooth size discrepancies in the different malocclusion groups, each group was compared with the results from Bolton's study. Measurements outside 2 SD were defined as exhibiting a clinically significant tooth size discrepancy.

\section{RESULTS}

\section{Analysis of error}

To ensure measurement accuracy, one month later 30 pairs of dental casts were randomly selected (ten from each malocclusion group) and the mesiodistal tooth widths were again measured by the same investigator. The overall ratios for each malocclusion group was calculated using the same method. A Non-parametric Wilcoxon Statistical test was applied to the first and second measurements. No statistically significant differences were found between the first and second measurement.

Table:- 1 Analysis of error for all measurements submitted to Non-parametric Wilcoxon statistical testing demonstrating no significant $(\mathrm{p}>0.05)$ difference between the two sets of measurements

\begin{tabular}{llllllll}
\hline Class & Measure & $\mathrm{n}$ & Minimum & Maximum & Mean & SD & P-value \\
\hline Class I & 1 & 10 & 86.86 & 93.62 & 90.15 & 1.75 & $0.8956(1=2)$ \\
& 2 & 10 & 87.0 & 93.44 & 90.05 & 1.70 & \\
Class II & 1 & 10 & 87.13 & 97.38 & 91.91 & 3.27 & $0.9815(1=2)$ \\
& 2 & 10 & 86.96 & 97.38 & 91.87 & 3.38 & \\
Class III & 1 & 10 & 88.14 & 94.43 & 91.38 & 2.00 & $0.9619(1=2)$ \\
& 2 & 10 & 88.2 & 94.50 & 91.43 & 2.05 & \\
\hline
\end{tabular}

Significance $p>0.005$

Table:-2: number and percentage distributions of the subjects among the different malocclusion with the mean age of the sample

\begin{tabular}{lllllll}
\hline & $\begin{array}{l}\mathrm{N} \\
(\text { Males })\end{array}$ & $\begin{array}{l}\mathrm{N} \\
(\text { Females })\end{array}$ & $\begin{array}{l}\mathrm{N} \\
(\mathrm{M}+\mathrm{F})\end{array}$ & $\%$ & $\begin{array}{l}\text { Mean age } \\
\text { (Years) }\end{array}$ & SD \\
\hline Class-I & 20 & 20 & 40 & 33.3 & 20.0 & 4.29 \\
Class-II & 20 & 20 & 40 & 33.3 & 18.7 & 3.59 \\
Class-III & 20 & 20 & 40 & 33.3 & 17.6 & 3.59 \\
Overall & 60 & 60 & 120 & 100 & 18.8 & 3.93 \\
\hline
\end{tabular}

Figure-1: Mean age of male and female

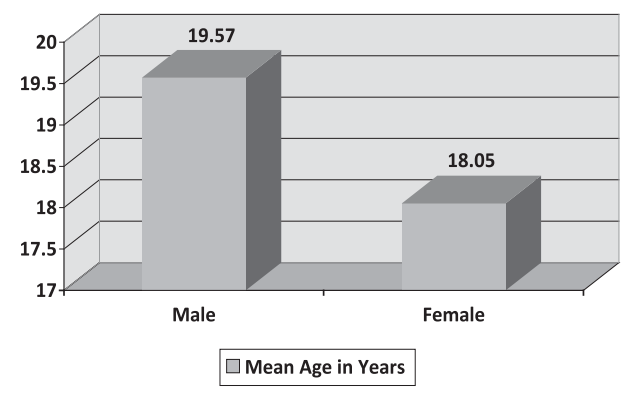

10 


\section{TOOTH MEASUREMENT-}

The mean, SD and statistical comparisons of the mesiodistal tooth measurements for males and females are shown in Table 3 . There were significant differences between genders for most of the teeth measured $(p<0,05)$

Mesio-distal dimensions of lower teeth in class III group has become larger when comparing with the class I and clas II group.

Table:3 The mean standard deviation (SD) and statistical comparison of mesiodistal tooth measurement for male and female

\begin{tabular}{|c|c|c|c|c|c|c|}
\hline & & \multicolumn{2}{|c|}{ Male $n=60$} & \multicolumn{2}{|c|}{ Female $\mathrm{n}=60$} & \multirow[b]{2}{*}{ P-value } \\
\hline & & Mean & SD & Mean & SD & \\
\hline \multirow[t]{6}{*}{ Maxillary } & Central incisor & 8.82 & 0.54 & 8.69 & 0.58 & 0.2113 \\
\hline & Lateral incisor & 7.15 & 0.56 & 6.98 & 0.76 & 0.1568 \\
\hline & Canine & 8.09 & 0.46 & 7.74 & 0.45 & $0.0001^{*}$ \\
\hline & 1st premolar & 7.30 & 0.48 & 7.11 & 0.47 & 0.0384 \\
\hline & 2nd premolar & 6.71 & 0.41 & 6.76 & 0.41 & 0.4883 \\
\hline & 1st molar & 10.75 & 0.53 & 10.45 & 0.62 & $0.0063^{*}$ \\
\hline \multirow[t]{6}{*}{ Mandibular } & Central incisor & 5.57 & 0.41 & 5.46 & 0.38 & 0.1167 \\
\hline & Lateral incisor & 6.18 & 0.44 & 6.01 & 0.37 & 0.0262 \\
\hline & Canine & 7.10 & 0.44 & 6.80 & 0.41 & $0.0003^{*}$ \\
\hline & 1st premolar & 7.24 & 0.44 & 7.15 & 0.48 & 0.2862 \\
\hline & 2nd premolar & 7.22 & 0.49 & 7.10 & 0.49 & 0.1654 \\
\hline & 1st molar & 11.18 & 0.60 & 10.85 & 0.61 & $0.0034^{*}$ \\
\hline
\end{tabular}

*Significance $p<0.005$

Table:-4 Statistical comparison of the mesiodistal tooth measurement between Class III and Class I malocclusion

\begin{tabular}{lllllll}
\hline & & \multicolumn{2}{c}{ Class $\mid \mathrm{n}=40$} & \multicolumn{2}{c}{ Class III $\mathrm{n}=40$} & \multirow{2}{*}{ P-value } \\
\cline { 3 - 6 } Maxillary & & Mean & SD & Mean & SD & 0.3367 \\
& Central incisor & 8.90 & 0.53 & 8.78 & 0.60 & 0.4597 \\
& Lateral incisor & 7.15 & 0.49 & 7.05 & 0.68 & 0.7565 \\
& Canine & 8.02 & 0.39 & 7.99 & 0.56 & 0.5961 \\
& 1st premolar & 7.28 & 0.33 & 7.33 & 0.54 & 0.2427 \\
2nd premolar & 6.72 & 0.36 & 6.82 & 0.35 & 0.7903 \\
& 1st molar & 10.67 & 0.58 & 10.70 & 061 & 0.8775 \\
& & & & & & 0.7786 \\
& Central incisor & 5.52 & 0.37 & 5.53 & 0.45 & 0.8211 \\
& Lateral incisor & 6.15 & 0.34 & 6.13 & 0.46 & 0.1691 \\
& Canine & 7.02 & 0.38 & 7.04 & 0.46 & 0.6081 \\
& 1st premolar & 7.21 & 0.33 & 7.35 & 0.54 & 0.4871 \\
\hline
\end{tabular}

Not in Significance $p>0.005$ 
Tooth Size Discrepancies among Different Malocclusions in a Bangladeshi Orthodontic population

Table:-5 Statistical comparison of the mesiodistal tooth measurement between Class III and Class II malocclusion

\begin{tabular}{lllllll}
\hline & & \multicolumn{2}{c}{ Class III $\mathrm{n}=40$} & \multicolumn{2}{c}{ Class II $\mathrm{n}=40$} & \multirow{2}{*}{ P-value } \\
\cline { 3 - 6 } Maxillary & \multicolumn{2}{c}{ Mean } & $\mathrm{SD}$ & Mean & $\mathrm{SD}$ & 0.1172 \\
& Central incisor & 8.78 & 0.60 & 8.58 & 052 & 0.6966 \\
& Lateral incisor & 7.05 & 0.68 & 6.99 & 0.81 & 0.0287 \\
& Canine & 7.99 & 0.56 & 7.74 & 0.44 & $0.0089^{*}$ \\
& 1st premolar & 7.33 & 0.54 & 7.01 & 0.50 & 0.0900 \\
& 2nd premolar & 6.82 & 0.35 & 6.65 & 0.50 & 0.0535 \\
1st molar & 10.70 & 0.61 & 10.44 & 0.57 & 0.6983 \\
& & & & & & 0.2141 \\
& Central incisor & 5.53 & 0.45 & 5.50 & 0.37 & 0.0321 \\
& Lateral incisor & 6.13 & 0.46 & 6.00 & 0.42 & $0.0053^{*}$ \\
& Canine & 7.04 & 0.46 & 6.80 & 0.49 & $0.0015^{*}$ \\
& 1st premolar & 7.35 & 0.54 & 7.03 & 0.4 & 0.0413 \\
\hline
\end{tabular}

*Significance $p<0.005$

Polygonic portrayal of cast analysis (Mesiodistal tooth diameter)

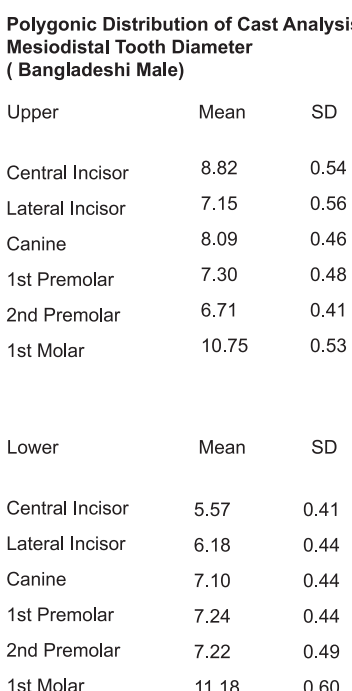

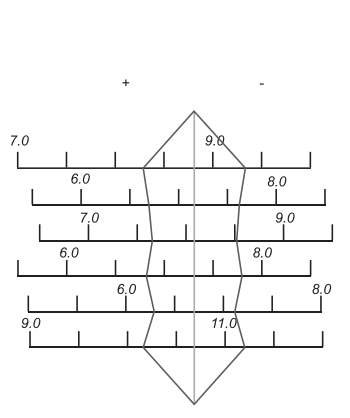

Polygonic Distribution of Cast Analysis Mesiodistal Tooth Diameter (Bangladeshi Female)

Upper

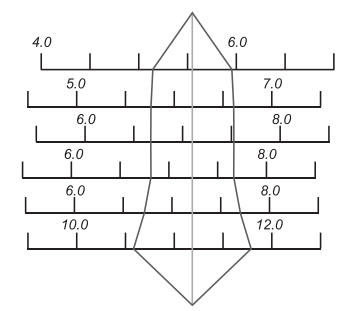

Lower

Central Incisor Lateral Incisor

Canine

1st Premolar

2nd Premolar
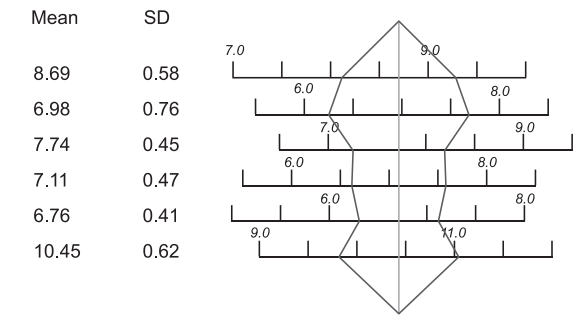

1st Molar

$\begin{array}{ll}\text { Mean } & \text { SD } \\ & \\ 5.46 & 0.38 \\ 6.01 & 0.37 \\ 6.80 & 0.41 \\ 7.15 & 0.48 \\ 7.10 & 0.49 \\ 10.85 & 0.61\end{array}$

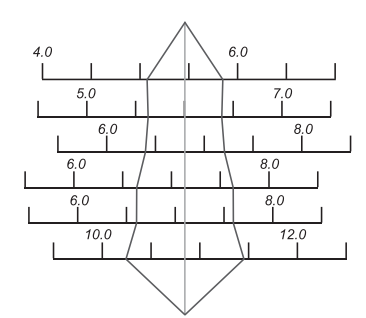


TSD AND GENDER-

Anterior, posterior and overall ratios for TSD for males and females are presented in table 6 . There were no statistically significant differences between males and females for the anterior ratios, posterior ratio and over all ratios. Although the TSD ratios were larger for males, the differences were not significant.

Table:-6 Anterior, posterior and overall tooth size ratios (\%) by sex and malocclusion form

\begin{tabular}{|c|c|c|c|c|c|c|c|c|c|}
\hline & \multicolumn{4}{|c|}{ Male } & \multicolumn{4}{|c|}{ Female } & \multirow[b]{2}{*}{ P-value } \\
\hline & Mean & SD & SE & Range & Mean & SD & SE & Range & \\
\hline \multicolumn{10}{|c|}{ Anterior ratio } \\
\hline Class I & 77.92 & 2.80 & 0.62 & $76.61-79.23$ & 77.49 & 2.87 & 0.64 & 76.14-78.83 & 0.6320 \\
\hline Class II & 78.70 & 3.88 & 0.86 & $76.88-80.51$ & 78.37 & 4.08 & 0.91 & $76.46-80.28$ & 0.7951 \\
\hline Class III & 78.70 & 3.28 & 0.73 & $77.16-80.24$ & 78.43 & 3.09 & 0.69 & $76.98-79.88$ & 0.7919 \\
\hline \multicolumn{10}{|c|}{ Posterior ratio } \\
\hline Class I & 102.96 & 2.90 & 0.65 & $101.60-104.32$ & 103.74 & 3.65 & 0.81 & $102.03-105.45$ & 0.4584 \\
\hline Class II & 103.81 & 2.55 & 0.57 & $102.62-105.01$ & 102.09 & 4.18 & 0.93 & $100.13-104.04$ & 0.1230 \\
\hline Class III & 103.61 & 3.70 & 0.82 & $101.88-105.34$ & 103.60 & 2.97 & 0.66 & $102.20-104.99$ & 0.9888 \\
\hline \multicolumn{10}{|c|}{ Over all ratio } \\
\hline Class I & 89.82 & 3.06 & 0.68 & $88.39-91.25$ & 91.06 & 2.18 & 0.48 & $90.03-92.08$ & 0.1505 \\
\hline Class II & 91.31 & 2.25 & 0.50 & $90.26-92.37$ & 90.56 & 3.25 & 0.72 & 89.04-92.09 & 0.4039 \\
\hline Class III & 91.58 & 2.62 & 0.58 & $90.36-92.81$ & 91.28 & 2.60 & 0.58 & $90.06-92.50$ & 0.7201 \\
\hline
\end{tabular}

Not in Significance $\mathrm{p}>0.005$

TSD AND BOLTON'S STANDARD

No statistically significant differences were found in anterior and overall ratios for every malocclusion group when comparing with the Bolton's standard. As there is no standard available for posterior ratio so it could not be compared. The table also shows that there were no significant differences in anterior ratio, posterior ratio or overall ratios among the malocclusion groups by ANOVA test.

Table:-7 Tooth size ratio of each malocclusion group compared with Bolton's figure

\begin{tabular}{|c|c|c|c|c|c|c|}
\hline & Mean & SD & SE & Range & t-test & ANOVA \\
\hline \multicolumn{7}{|c|}{ Anterior ratio } \\
\hline Bolton & 77.2 & 1.65 & 0.22 & $74.5-80.4$ & & \multirow{4}{*}{0.428} \\
\hline Class I & 77.7 & 2.81 & 0.44 & $70.8-81.86$ & 3.519 & \\
\hline Class II & 78.5 & 3.93 & 0.62 & $71.53-91.75$ & 1.142 & \\
\hline Class III & 78.5 & 3.15 & 0.49 & $70.00-84.31$ & 2.147 & \\
\hline \multicolumn{7}{|c|}{ Posterior ratio } \\
\hline Class I & 103.3 & 3.28 & 0.51 & $96.82-110.13$ & & \multirow{3}{*}{0.683} \\
\hline Class II & 102.9 & 3.53 & 0.55 & $93.72-108.06$ & & \\
\hline Class III & 103.6 & 3.31 & 0.52 & $96.64-110.53$ & & \\
\hline \multicolumn{7}{|c|}{ Over all ratio } \\
\hline Bolton & 91.3 & 1.91 & 0.26 & $87.5-94.8$ & & \multirow{4}{*}{0.260} \\
\hline Class I & 90.4 & 2.69 & 0.42 & $80.04-95.59$ & 1.45 & \\
\hline Class II & 90.9 & 2.79 & 0.44 & $84.51-97.38$ & 2.006 & \\
\hline Class III & 91.4 & 2.58 & 0.40 & $83.97-98.62$ & 0.810 & \\
\hline
\end{tabular}

Not in Significance $\mathrm{p}>0.005$ 
PREVALANCE OF TOOTH SIZE DISCREPANCY

Significance anterior and overall tooth size discrepancies outside two standard deviation from the Bolton means were found in $31 \%$ and $11.6 \%$ of all the malocclusion subjects respectively. The chi squre tests demonstrated no significant differences in the distribution of subjects with anterior or overall tooth size discrepancies among the malocclusion groups.

Table:-8 Distribution of subjects with anterior and overall tooth size discrepancies

\begin{tabular}{|c|c|c|c|c|}
\hline & $\begin{array}{l}\text { Outside-2SD } \\
<73.89\end{array}$ & $\begin{array}{l}\text { Anterior ratio No (\%) } \\
(-2 \mathrm{SD})-(+2 \mathrm{SD}) \\
73.90-80.50\end{array}$ & $\begin{array}{l}\text { Outside +SD } \\
>80.51\end{array}$ & P-value \\
\hline Class-I & $5(4.2)$ & $30(25.0)$ & $5(4.2)$ & 0.097 \\
\hline Class-II & $3(2.5)$ & $25(20.8)$ & $12(10.0)$ & \\
\hline \multirow[t]{2}{*}{ Class-III } & $2(1.7)$ & $28(23.3)$ & $10(8.3)$ & \\
\hline & $\begin{array}{l}\text { Outside-2SD } \\
<87.47\end{array}$ & $\begin{array}{l}\text { Overall ratio No (\%) } \\
\text { (-2SD)-(+2SD) } \\
87.48-95.12\end{array}$ & $\begin{array}{l}\text { Outside +SD } \\
>95.13\end{array}$ & \\
\hline Class-I & $4(3.3)$ & $35(29.2)$ & $1(0.8)$ & 0.510 \\
\hline Class-II & $4(3.3)$ & $34(28.3)$ & $2(1.7)$ & \\
\hline Class-III & $2(1.7)$ & $37(30.8)$ & $1(0.8)$ & \\
\hline
\end{tabular}

Not in Significance $\mathrm{p}>0.005$

Title:- Bar diagram of subjects with anterior tooth size discrepancies

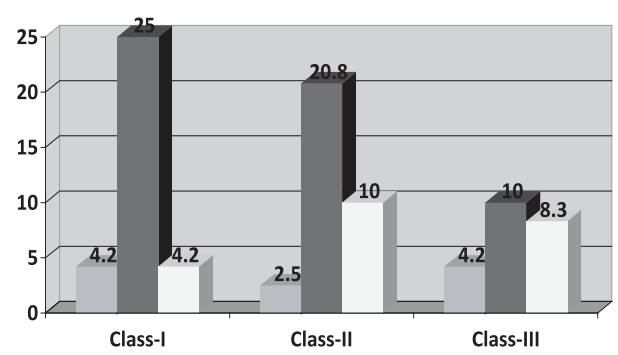

Outside -2SD <73.89 (-2SD)-(+2SD) 73.90-80.50 $\square$ Outside +2SD >80.51
Title:- Bar diagram of subjects with overall tooth size discrepancies

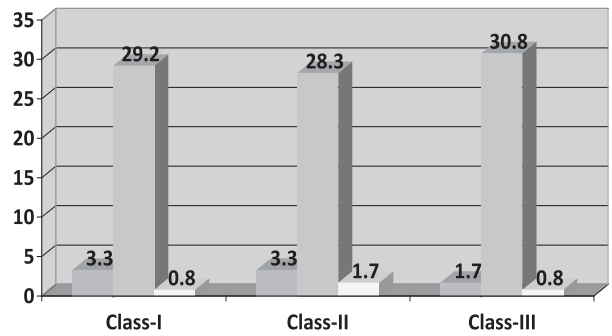

Outside -2SD <87.47 $\square$ (-2SD)-(+2SD) 87.48-95.12 $\square$ Outside +2SD >95.13

TSD IN BANGLADESHI ORTHODONTIC POPULATION

Table 9 Shows the mean anterior, posterior and overall tooth size ratios of Bangladeshi population

\begin{tabular}{lllll}
\hline Group & Mean & SD & SE & Range \\
\hline Anterior Ratio & 78.2 & 3.33 & 0.30 & $70-91.75$ \\
Posterior ratio & 103.30 & 3.36 & 0.30 & $93.72-110.53$ \\
Overall Ratio & 90.94 & 2.70 & 0.24 & $80.04-98.62$ \\
\hline
\end{tabular}




\section{Table-10 Anterior and overall tooth size ratios in different populations}

\begin{tabular}{|c|c|c|c|c|}
\hline Population & Author & $\begin{array}{l}\text { Sample } \\
\text { size }\end{array}$ & $\begin{array}{l}\text { Anterior } \\
\text { ratio (\%) }\end{array}$ & $\begin{array}{l}\text { Overall } \\
\text { ratios (\%) }\end{array}$ \\
\hline \multirow[t]{3}{*}{ White Americans } & Bolton (1958) & 55 & 77.2 & 91.3 \\
\hline & Crosby and Alexander (1989) & 109 & 77.5 & 91.4 \\
\hline & Smith et al. (2000) & 108 & 79.6 & 92.1 \\
\hline Black Americans & Smith et al. (2000) & 60 & 79.3 & 93.1 \\
\hline \multirow[t]{2}{*}{ Spanish } & Smith et al. (2000) & 60 & 80.5 & 93.4 \\
\hline & Paredes et al. (2006) & 100 & 78.32 & 91.97 \\
\hline Dominican & Santoro et al $(2000)$ & 54 & 78.1 & 91.3 \\
\hline Peruvian & Bernable et al (2004) & 200 & 78.09 & 90.79 \\
\hline Brazilian & Araujo and Souki (2003) & 300 & 78.18 & \\
\hline \multirow[t]{2}{*}{ Chinese } & Ta et al (2001) & 110 & 77.5 & 90.9 \\
\hline & Nie and Lin (1999) & 300 & 81.52 & 91.27 \\
\hline Saudi Arabian & Al-Tamini and Hashim (2005) & 65 & 77.4 & 91.4 \\
\hline \multirow[t]{2}{*}{ Turkish } & Uysal et al (2005) & 710 & 78.26 & 89.88 \\
\hline & Akyalein et al (2006) & 152 & 7815 & 91.34 \\
\hline Jordanian & lyad K Al-Omari (2008) & 367 & 78.6 & 92.2 \\
\hline Bangladeshi's & Present study & 120 & 78.2 & 90.94 \\
\hline
\end{tabular}

\section{DISCUSSION}

In this study mean age for males was 19.57 and for females it was 18.05 . This relatively young age group was chosen in accordance with the study of Doris et al.(1981) to minimize the alteration of the MD dimensions due to attrition, restorations or caries. Consequently, the effect of these factors on actual MD tooth widths was minimal. The subjects of this current study were all randomly selected Bangladeshi and thus proportionately representative of malocclusion type.

The results demonstrated a significant difference in mesiodistal tooth width between males and females for most tooth. This is in agreement with result of the study on the Jordanian population which found statistically significant differences between males and females for mesio distal crown diameters (Hattab et al,1996,Iyad k. AL-Omari et al, 2008).Other investigators have found the same sexual dimorphism in tooth size measurements 6 .(Ballard,1944, Lavelle, 1972)
This study found significantly larger mesiodistal dimensions of mandibular tooth in Class III malocclusion subjects when compared with Class I and Class II subjects which supports the study conducted by levelle,1972;6 Sperry et al,1977,7 speculated that greater means in Bolton's ratio in these classes might be due to etiological factors that lead to mandibular prognathism and may also be associated with increased MD dimensions of upper anterior teeth in class II subjects that lead to maxillary prognathism. Further studies are needed to clarify wheather a correlation exists between increased growth of the jaws and increased MD dimension of anterior teeth.

Polygonic portrayal of cast analysis of mesiodistal tooth dimension of Bangladeshi population from this study has established the norm for mesiodistal tooth dimension for our male and female population. This is the first attempt to present mesiodistal tooth diameter for upper and lower jaw in polygonic distribution format in Bangladesh. The super imposition also dictate the difference between the mesiodistal diameter of male and 
female teeth.

The results of the present investigation showed no statistically significant differences between males and females in anterior ratio, posterior ratio and overall ratio for each malocclusion group. Although the TSD ratios for males are larger, the differences were small. These findings are in agreement with most studies on TSD8-12 Other research, however, has shown a statistically significant difference in tooth size ratios for both genders. $6,13,14$

Studies conducted in Bangladesh on anterior tooth size discrepancies by Rahman M M,2007;15 Ali Wazed M, 200816 in the Department of Orthodontics and Dentofacial Orthopedics, Dhaka Dental college and Hospital, Dhaka, and by Hasan Nazmul M,2010;17 in the Department of orthodontics, BSMMU, Dhaka. They also did not find any significant difference in anterior ratio between gender and with the Bolton standard. The larger standard deviations of both anterior and overall ratios of the present study than for Bolton's study might have been caused by the fact that all of our subjects had malocclusions and Bolton's subject had excellent occlusion.

The results of this study support the findings of Uysal et al, 18 who also found no significant differences in anterior or overall ratio when comparing class I, class II division 1, class II division 2 and class III malocclusion subjects with the corresponding ANB angles. Crosby and Alexander(1989), 19 and Akyalcin et al (2006) 12 showed no significant differences in anterior and overall ratio among malocclusion groups, as confirmed in this study.

Our result are in disagreement with Nie and Lin, (1999) 8 Araujo and Souki,(2003) 10 and Fattahi et al, (2006) ${ }^{14}$ who reported statistically significant differences in tooth size ratios among different Angle malocclusion groups. They showed a tendency toward greater tooth size ratios among subjects with class III malocclusion than among those with other classes of malocclusion in Chinese, Brazilian, and Iranian population. The probable reason for these different results might be population and malocclusion specific.

When comparing the anterior and overall tooth size ratios of the present study with the Bolton's standard no statistically significant difference have been found between the malocclusion groups. The means of the tooth size ratios were similar to Bolton's measurement as well as with those of Crossby and Alexander (1989), 19 The only difference was in the higher SD in the present study as compared with Bolton's standards that could be attributed to the difference in sample size.

Few studies have been conducted on posterior tooth size discrepancy 14 on Iranian and Croatian population respectively. They did not find any statistically significant gender difference which is similar to our study. The means of the posterior ratio for Iranian population were 104.12 with SD 3.40 and for Croatian population it was 104.88 with SD 3.06 which is nearly close to our findings of posterior ratio 103.30 with SD 3.36.
The majority of investigations on TSD have chosen value outside $2 \mathrm{SD}$ as an indication of a clinically significant TSD. In the present study, the percentages of clinically significant TSD of the anterior and overall ratio were 31 and 11.6 percent respectively which is similar in rate with the study conducted by Freeman et al (1996) $(30 \%)^{20}$ and Barbara et al(2010) $(31.2 \%)^{21}$ for anterior ratio and Freeman et al(1996) (13\%) and Santoro et al (2000) $(11 \%)^{22}$ and Barbara et al (2010) $(10.2 \%)^{21}$ for overall ratio.

Results of clinically significant TSD for anterior ratio was 34.5 per cent and 36.23 per cent in two previous studies done on our population ${ }^{16,17}$ But they have chosen values outside 1 SD from Bolton mean.

Our findings of lower prevalence rates of clinically significant discrepancy for the overall ratio than for the anterior ratio are supported by studies conducted by Freeman et al(1996) 20 and Santoro et al (2000)22 and Barbara et al (2010)21 and may be explained by the fact that anterior teeth have much greater tooth size deviation, especially in the subjects with malocclusion.

\section{CONCLUSION}

On the basis of the results of this investigation, following conclusion can be drawn

1. No statistically significant sex differences were found in anterior, posterior and overall ratios in each malocclusion groups.

2. Statistically significant differences were found comparing the mesiodistal dimensions of tooth in maxilla and mandible for males and females.

3. No significant differences in anterior, posterior and overall ratio were found among the malocclusion groups when comparing with Bolton's standard.

4. Bolton's values can be used with confidence in a Bangladeshi Orthodontic population.

5. Prevalence of clinically significant intermaxillary TSD is $31 \%$ and $11.6 \%$ in anterior ratio and overall ratios respectively.

\section{REFERENCES}

1. Andrews L F1972.The six keys to normal occlusion. American Journal Of Orthodontics and Dentofacial Orthopedics 62;296=309

2. Proffit, W.R., 2000, Orthodontics. 3rd edition. St Louis, Mosby, 170.

3. Neff C W 1957 The size relationship between the maxillary and mandibular anterior segments of the dental arch. Angle Orthodontist27;138-147

4. Bolton WA 1958 disharmonies in tooth size and its relation to the analysis and treatment of malocclusion. Angle Orthodontist28,113130

5. Bolton WA 1962 The clinical application application of a tooth size 
analysis. American Journal Of Orthodontics and Dentofacial Orthopedics 48;504-529

6. Levelle C LB1972 Maxillary and mandibular tooth size in different racial groups and different occlusal categories. American Journal Of Orthodontics and Dentofacial Orthopedics 61;29-37

7. Sperry T P,Worms F W, Isaacson R J ,Spiedel T M 1977 Tooth size discrepancy in mandibular prognathism. American Journal Of Orthodontics and Dentofacial Orthopedics 72;183-190

8. Nie Q, Lin J 1977 Comparison of Comparison of intermaxillary tooth size discrepancies among different malocclusion groups. American Journal Of Orthodontics and Dentofacial Orthopedics $116 ; 539-544$

9. Alkofide E, Hashim H 2002 Intermaxillary tooth size discrepancy among different malocclusion classes; a comparative study.Journal of Clinical Pediatric Dentistry 24;383-387

10. Araujo E, Souki M 2003 Bolton anterior tooth- size discrepancies among different malocclusion groups. Angle Orthodontist 73;307313

11. Al-Tamimi T, Hashim HA2005 Bolton tooth- size ratio revised World Journal of Orthodontics 6;289-295

12. Akyalcin S, Dogan S, Dincer B, Erdinc AM, Oncag G 2006 Bolton tooth- size discrepancies in skeletal class I individuals presenting with different dental Angle classification. Angle Orthodontist $76 ; 637-643$

13. Smith S S, Buschang P H, Watanabe E2000 Interarch tooth size relationship of 3 populations;does Bolton' analysis apply? American Journal Of Orthodontics and Dentofacial Orthopedics 117;169-174
14. Fattahi HR, Pakshir HR,Hedayati z 2006 Comparison of tooth size discrepancies among different malocclusion groups.European Journal of Orthodontics 28;491-495

15. Rahman M M,2007;Estimation of arch Form, arch width and arch length in normal occlusion.Dhaka DDental College.

16. Ali W M 2008;A study on Bolton Anterior tooth size discrepancies among diffreent malocclusion groups.

17. Hasan N M, 2010.Anterior tooth discrepancies among different malocclusion group in the Department of Orthodontics,BSMMU.

18. Uysal T, Sari z ,Bascifiti F A ,Memili B 2005 Intermaxillary tooth size discrepancy and malocclusion; is there a relation? Angle Orthodontist 75;208-213

19. Crossby DR,AlexanderCG 1989The occurance of tooth size discrepancy among differentmalocclusion groups. American Journal Of Orthodontics and Dentofacial Orthopedics 48;504-529

20. Freeman JE, Maskeroni AJ, Lorton L1996 Frequency of Boltonr tooth- size discrepancies among Orthodontic patients. American Journal Of Orthodontics and Dentofacial Orthopedics 110;24-27

21. Barbara Wedrychowska-szulc, Joanna Janiszewska-Olswska,2010 Overall and anterior Bolton ratio in Class 1, ,II, and III orthodontic patients .European Journal of Orthodontics 32;313-318

22. Santoro M, Ayoub ME,Pardi V A, Cangialosi T J 2000 Mesiodistal crown dimensions and tooth size discrepancy of the permanent dentition of Dominician Americans. American Journal Of Orthodontics and Dentofacial Orthopedics 70;303-307

\section{Correspondence:}

Lt Col Dr MD Liakat Ali Hyder

BDS, FCPS

Graded Specialist in Orthodontics,

$\mathrm{CMH}$, Chittagong Cantt.

Mobile : +880-01715921910

E mail liakathyder@gmail.com 